\title{
Identifying Effects of Institutional Resources and Support on Computing Faculty Research Productivity, Tenure, and Promotion
}

\author{
Monica M. McGill \\ Bradley University, \\ Peoria, IL, USA \\ mmcgill@bradley.edu
}

\author{
Amber Settle \\ DePaul University, \\ Chicago, IL, USA
}

asettle@cdm.depaul.edu

\begin{abstract}
As previous research has shown, increasing research productivity in postsecondary institutions provides direct benefits to those institutions, departments, and individual faculty, and this research productivity is often dependent on institutional support. Understanding this relationship is important for doctoral students, as many enter academia after completing their studies, and their success as faculty can be highly dependent on their success in establishing a strong research program. The authors conducted a study to determine if individual computer science faculty receive institutional resources and support congruent with research requirements set forth in tenure and promotion guidelines. The results identify hidden requirements for tenure and promotion, including an emphasis on research collaboration, and find that the level of support in the 2009-10 academic year remained stagnant from the previous year. Results indicate that faculty are not satisfied with their level of institutional support and that the three areas in which additional support would enable them to increase their research productivity include staff support, release time, and funding for attending conferences. Results also indicate that untenured faculty receive less staff support, less funding for summer salaries and workshops and training, and less funding for improvements to office space or facilities than their tenured colleagues.
\end{abstract}

Keywords: Tenure, promotion, resources, computing, faculty, institutions, Taulbee survey

\section{Introduction}

Over the last few decades, there has been a growing body of literature on the research productivity of faculty in higher education (Athey \& Plotnicki, 2000; Blackburn, Bieber, Lawrence, \& Trautvetter, 1991; Brocato \& Mavis, 2005; Caffarella \& Zinn, 1999; Dennis, Valachich, Fuller, \& Schneider, 2006; Dundar \& Lewis, 1998; Fairweather, 2002; Freedenthal, Potter, \& GreinsteinWeiss, 2008; Glassick, Huber, \& Maeroff, 1997; Meho \& Spurgin, 2005). The literature explores

Material published as part of this publication, either on-line or in print, is copyrighted by the Informing Science Institute. Permission to make digital or paper copy of part or all of these works for personal or classroom use is granted without fee provided that the copies are not made or distributed for profit or commercial advantage AND that copies 1 ) bear this notice in full and 2) give the full citation on the first page. It is permissible to abstract these works so long as credit is given. To copy in all other cases or to republish or to post on a server or to redistribute to lists requires specific permission and payment of a fee. Contact Publisher@InformingScience.org to request redistribution permission. a number of areas, including a longitudinal study of tenure and promotion requirements (Bunton \& Mallon, 2007; Youn \& Price, 2009), methods to measure research productivity (Athey \& Plotnicki, 2000; Fairweather, 2002; Glassick et al., 1997; Meho \& Spurgin, 2005), and identification of factors that influence productivity (Blackburn et al., 1991; Brocato \& Mavis, 2005; Cafferella \& Zinn, 1999; Freedenthal et al., 
2008). The interest in this area is understandable since increasing research productivity and scholarly excellence provides direct benefits to institutions and departments as well as individual faculty (Amo, Ada, \& Sharman, 2012; Dundar \& Lewis, 1998; Research Assessment Exercise, 2008; Youn \& Price, 2009). An understanding of the factors that contribute to faculty research productivity is especially important for doctoral students in computing, since over $41 \%$ of graduating computing doctoral students in the United States and Canada took positions in academia in the 2008-09 academic year (Zweben, 2010). Doctoral students transitioning to faculty positions need to both evaluate potential employment situations and to negotiate for resources that will enable their eventual success as faculty researchers.

Means of support for producing quality research can be key and broad ranging for faculty. Research support can be defined as any resource that is provided to enhance a faculty member's ability to engage in scholarship. Previous work has defined research support to include three main areas: time to pursue scholarship, funding to pursue scholarship, and technical expertise, assistance, and training (Freedenthal et al., 2008). Other research examines institutional resources and support in relation to several specific fields, such as education, geography, library and information science, nursing, medicine, and social work, and contains an overview of different types of support including data for faculty salaries, physical space for offices, labs, and meetings rooms, research funds, mentorship initiatives, and academic staff development programs (Brocato \& Mavis, 2005; Bunton \& Mallon, 2007; Conrad, 1998; Dunham-Taylor, Lynn, Moore, McDaniel, \& Walker, 2008; Fletcher \& Patrick, 1998; Greene, O'Connor, Good, Ledford, Peel, \& Zhang, 2008; Gruppen, Frohna, Anderson, \& Lowe, 2003; Meho \& Spurgin, 2005; Piercy, Giddings, Allen, Dixon, Meszaros, \& Joest, 2005; Solem \& Foote, 2004).

In the United States and Canada, the Computing Research Association (CRA) administers the Taulbee Survey, an annual report of the profiles of computing faculty (Zweben, 2010). The Taulbee Survey includes information about salaries and some basic information about space and resources. In addition, there are studies that examine the disconnect between publication requirements for promotion and tenure and information systems/technology faculty publication rates (Athey \& Plotnicki, 2000; Dennis et al., 2006). But there are few studies and very little data that examine broad institutional resources and support necessary for computer science faculty to be successful in meeting their tenure and promotion guidelines. Specifically, there are no studies or published research for computing faculty that include a wide spectrum of factors that can impact research productivity, such as funding for travel and professional meetings, funding for equipment, summer stipends, mentoring programs, and training. This puts doctoral students in the computing field into a difficult position, precisely at a time when competition for faculty positions has increased and it appears that postdoctoral positions may be increasingly used by recent computing PhDs as a stopgap employment situation (CRA, 2012). Without a clear understanding of the factors that influence research productivity, particularly factors that involve institutional resources, computing doctoral students will have a difficult time making informed employment decisions.

The researchers of this study were interested in learning if individual computer science faculty receive institutional resources and support congruent with their needs for successfully meeting research aspects of their tenure and promotion guidelines. Specifically, the overarching questions for this study were:

- What types of institutional resources and support for research do individual computer science faculty receive?

- Do individual computer science faculty believe that the institutional resources and support they receive for research is congruent with their requirements for tenure/promotion? 
- Is there a relationship between the amount of institutional resources and support and research productivity, collaboration (internal and/or external), faculty satisfaction, faculty position, and tenure and promotion?

This research is useful for many reasons due to its basic collection of demographic data on tenure and promotion. It is useful for faculty at institutions involved in writing tenure and promotion guidelines. Administrators responsible for allocating research and support funds for computer science departments and/or for individual faculty members may find the data helpful. It may serve as a support reference for administrative requests for additional departmental funding. It will also provide existing computer science faculty with a point of reference when requesting annual funding for research and support and should serve as a reference for doctoral students and others being hired into computer science faculty positions when negotiating terms of employment.

This research, however, takes this information one step further. The research included a look at tenure and promotion requirements that may not be formally required, but may be informally required as part of the culture. Since it is known that higher faculty satisfaction correlates to higher faculty retention (Dee, 2004; Dunham-Taylor et al., 2008; Ehrenberg, Kasper, \& Rees, 1991; Olsen, Maple, \& Stage, 1995; Piercy et al., 2005; Rosser, 2005), this research also investigates the relationship, if any, between support levels and faculty satisfaction.

\section{Research Productivity in Higher Education}

Research productivity is an important element in the attainment of tenure and promotion in US and Canadian institutions (Carnegie Foundation, 1991; CRA, 1999). Previous research has shown that there is a relationship between scholarly excellence at an institution and the institution's reputation and prestige. In turn, this often leads to more institutional resources, since a good reputation for excellence in scholarship can attract high-ability students to the institution as well as improve the chances of obtaining external funding (Dundar \& Lewis, 1998). Such changes can then result in growth at the institution, which may further contribute to research productivity. One study found that management scholars with higher status were more likely to be published in journals with higher impact factors, even when their manuscripts were not of higher quality (Amo et al., 2012).

This section examines some of the types of institutional resources and support required for successful research productivity, faculty satisfaction, and a summary of what is currently known about computing faculty support.

\section{Defining and Measuring Research Productivity}

Measuring the research productivity of faculty is a complex issue, with many contributing factors. Productivity has been measured at a variety of levels, including at the level of individual faculty, at the unit level (for example, the department), and at the institutional level (Dundar and Lewis 1998). Research productivity has been measured as the quantity and/or quality of the artifacts produced by faculty scholarship (Athey \& Plotnicki, 2000; Brocato \& Mavis, 2005; Dennis et al., 2006; Dundar \& Lewis, 1998; Meho \& Spurgin, 2005; Park \& Riggs, 1993). The criteria that have been used in measuring productivity vary by institution and discipline, and faculty promotion and tenure is typically based in part on those criteria. Previous studies have found that both productivity criteria and promotion and tenure requirements also change over time, as disciplines and institutions change, grow, or mature (Bunton \& Mallon, 2007; Dennis et al., 2006; Youn \& Price, 2009).

A number of variables can impact research productivity. Previous research has found that faculty at larger institutions may have greater opportunities for collaboration with colleagues, larger insti- 
tutions are more likely to attract high-quality researchers, and larger institutions may have more resources and more freedom in how resources are utilized (Dundar \& Lewis, 1998). Economic conditions can also have a profound impact on faculty research productivity, and institutional support for scholarship can be restricted or eliminated during difficult economic times. This is particularly true for travel funding which may be restricted to faculty with accepted papers or may be eliminated altogether (Petry \& Kenney, 1991). Other studies have shown that age, gender, socioeconomic status, experience, and educational background can impact faculty productivity, with the combination of age and experience showing a particularly strong correlation with research productivity (Dundar \& Lewis, 1998).

With respect to publication venues, the situation for computer science faculty differs from many other academic disciplines. Archival journals are often the place where faculty are required to publish in higher education, but this is a somewhat controversial topic in computing. While information systems or information technology faculty may have promotion and tenure requirements that emphasize elite journals (Athey \& Plotnicki, 2000; Dennis et al., 2006), conference proceedings often play a large part as a publication venue for computer science faculty (Zweben, 2010). This is supported by the Computing Research Association (CRA, 1999) guidelines, but not without controversy. A recent study using a bibliometric approach has shown that journal articles have a greater impact than conference publications in computer science (Franceschet, 2010), possibly causing a reconsideration of future preferred venues.

Nevertheless, the CRA submits that conference publication is preferred in the field of computing, and computing artifacts can also serve as valid evidence of research productivity (CRA, 1999). Conference publications provide a valuable forum for timely dissemination of current research. Within the field, "conference publication is both rigorous and prestigious" and "assessing artifacts requires evaluation from knowledgeable peers" (CRA, 1999, p. B). The former requires conference attendance for authors, while the latter requires networking among peers within one's specific research area.

Indeed, faculty activities and networking have been recognized as an important area of research productivity. It is important for faculty to engage in context-sensitive activities and intentional networking opportunities for a variety of reasons, including securing both internal and external funding as well as finding the right venue for publishing books and articles (Conrad, 1998; Shaw, 2002). Shaw also stated the importance of establishing peer recognition and support for research agendas in order to increase productivity. Such support is important for more than publications as it can also often improve a faculty member's professional network, which can be crucial in securing external funding and preventing research isolation (Shaw, 2002).

Since conference publications, presentations, and attendance are important in measuring research productivity for computer science faculty, funding to engage in research and attend conferences is a vital part of the institutional funding for scholarship. Researchers have previously established positive relationships between faculty support levels and faculty research productivity (Dundar \& Lewis, 1998; Freedenthal et al., 2008; Gruppen et al., 2003; Thomas, Diener-West, Canto, Martin, Post, \& Streiff, 2004), with Dundar and Lewis concluding that faculty with financial research support also had higher research performance and that average faculty research productivity for faculty in private institutions was significantly more than average faculty research productivity in public universities (p. 622). Institutional and departmental attributes associated with research productivity included availability of technology and computing facilities, workload policies, and the availability of leave, travel, and institutional funds for research. 


\section{Levels of Funding and Support}

There is little to no centralized information on levels of funding and support for faculty. The National Center for Education Statistics (NCES) collected data in 1993 and 1999 from faculty at academic institutions as part of its National Study of Postsecondary Faculty (NSOPF), including some information about institutional resources and support. In 1993, only 58\% of respondents had institutional or departmental funding available for use over the previous two years (U.S. Department of Education, 1993). 39\% of those who had it available used it. Of those who used it, $63 \%$ felt those funds were sufficient, while $27 \%$ did not believe the funds were adequate. In 1999, faculty were asked to categorize their use of professional travel funding from their institutions, with $46 \%$ stating that institutional funds were used for travel (U.S. Department of Education, 1999). Faculty were of the opinion that in the years preceding 1999, it had become more difficult for faculty to obtain external funding (15\% strongly agreeing and 52\% agreeing).

Particularly troubling is a study that found untenured faculty reported stressful and unbalanced lifestyles, with work expectations exceeding assigned workloads for several institutions (Greene et al. 2008). Previously, Schuster (1986) researched higher education and discovered a steady reduction in faculty support. Support was defined as secretarial and clerical, library budgets, research instrumentation, faculty travel, office space, campus maintenance, faculty evaluation processes, and poorly-prepared students. He also noted that resources were becoming scarcer, and competition for those resources was a concern for faculty.

\section{Job Satisfaction and Retention}

The NCES also collected data about overall job satisfaction in the NSOPF reports from 1993, 1999, and 2004 (U.S. Department of Education, 1993, 1999, 2004). In 1993, faculty reported being very satisfied (38\%) or somewhat satisfied (47\%) in their positions at their institutions, though much less satisfied with the time it took them to keep current in their field. In 1999, the overall job satisfaction remained the same, with $40 \%$ reporting being very satisfied and $45 \%$ reporting being somewhat satisfied. The time to keep current in their field also remained unchanged. In 2004, overall job satisfaction remained high, with $48 \%$ reporting being very satisfied and $41 \%$ being somewhat satisfied.

Intrinsic motivation factors appear to be a major part of faculty satisfaction, while extrinsic factors, like university support, salary, and university structure and reward system, play a role in how dissatisfied faculty are in their positions (Olsen, 1993). Retention rates for faculty have been historically stable, and compensation levels play a strong role in faculty retention (Ehrenberg et al. 1991). Faculty who network both on campus and at academic conferences increase their satisfaction levels and their job performance (Solem \& Foote, 2004, p. 889). In fact, faculty who do not engage in networking can encounter research isolation and often struggle to find department and institutional resources, including adequate library resources and support for administering external research grants.

Institutions with faculty who are dissatisfied with their levels of support may face problems with retention. This is particularly troublesome for disciplines where recruitment is already an issue such as nursing (Dunham-Taylor et al., 2008) or computing (Camp, 1997), or for particular types of institutions (Dee, 2004). Administrators at many institutions are concerned with the retention of faculty from underrepresented groups and provide mentoring to improve both faculty retention and satisfaction (Conrad, 1998; Dee, 2004; Dunham-Taylor et al., 2008; Fletcher \& Patrick, 1998; Gruppen et al., 2003; Piercy et al., 2005).

Particularly interesting for this study is previous research that shows significant disciplinespecific variations in faculty turnover rates (Xu, 2008). The study showed that research support was critical for faculty in computing, and that stress caused by time constraints was another im- 
portant factor that increased the possibility of turnover. Xu (2008) concluded that disciplinespecific information was important for institutional administrators and policy makers to make effective faculty retention decisions.

\section{Existing Data on Institutional Resources and Support for Computing Faculty}

Beyond profiles of faculty and students, the Taulbee Survey collects data about computing faculty every three years (Zweben, 2010). The 2008-09 survey gathered this data, including information on teaching loads, department support staff, and space. Though external funding sources were indentified for these institutions, no information was collected about internal funding faculty received.

Teaching loads could be reduced for various reasons, with half of the institutions allowing a reduction for strong research involvement. The median amount of administrative support staff, computer support staff, and research support staff were reported in the survey results. Department space, including conference room and seminar space, was also included.

\section{Summary}

The literature illustrates that research productivity is important not only for faculty to receive tenure and promotion, but also for the prestige of the institution, which in turn can lead to additional external funding and interest in the institution on the part of students, faculty, and other stakeholders.

Measuring research productivity is a complex issue, and productivity is measured in different ways depending in the granularity of the situation, the discipline, the type of institution, and the maturity of the field. To be productive researchers, faculty require resources for networking, development, and conducting experiments and studies. Faculty at larger, more well-funded, or private institutions have advantages, although difficult economic times impact all institutions. Faculty who lack the ability to network may feel isolated, leading to an increase in dissatisfaction. Faculty demographics are correlated with research productivity, with age and experience showing a particularly strong correlation. As may be expected, untenured faculty report stressful and unbalanced lifestyles, but situations like this create problems for disciplines where faculty retention is an issue. Mentoring programs attempt to improve the retention of underrepresented faculty, but there are significant discipline-specific variations in faculty turnover rates. Information about faculty characteristics in specific disciplines is crucial for institutions to make effective administrative decisions.

The needs of computer science faculty differ from faculty in other disciplines. Publications to conference proceedings require resources for travel for presentations, and software and hardware required to conduct research can be costly. The ability to travel is not only important for publications since networking can be crucial in securing external funding, upon which many computing faculty rely in order to enhance their research productivity.

However, an exact measure of the type and amount of institutional resources and support for research that computing faculty receive is unknown. Though the 2008-09 Taulbee Survey covers such important items as faculty salary, teaching loads, space, support staff, and sources of research funding, there is no information available on whether the level of institutional resources and support is sufficient for faculty to attain the level of research productivity required for tenure and promotion and whether or not this relates to the many factors that impact job satisfaction. Given changing trends in employment for recent computer science Ph.D.s, with increasing use of postdoctoral positions and decreasing availability of tenure-track academic positions, understand- 
ing institutional research support is crucial for computing doctoral students aspiring to work in academic settings as well as their advisors.

\section{Methodology}

To answer the research questions, we chose a quantitative study and created a cross-sectional survey to collect data needed to explore the questions (Creswell, 2008). The questions on the survey were derived from a wide variety of studies in other academic fields and types of institutions, with the work by Dundar and Lewis (1998) being particularly influential (Conrad, 1998; Dundar \& Lewis, 1998; Freedenthal et al., 2008; Olsen, 1993; Shaw, 2002; Schuster 1986, Solem \& Foote, 2004). For the purposes of this study, the definition of faculty scholarship provided by Freenthal et al. (2008) was adopted and included publication of peer-reviewed articles, receipt of external funding (funding for research whose source is outside of the institution), conference presentations, authored or edited books, and published book chapters. Various types of institutional resources and support were established through the literature and were included in the survey questions; however, we also provided an "Other" entry field for participants to add additional resources or support that they received. In the survey, internal collaboration was defined as collaboration with researchers within the participant's institution, while external collaboration was collaboration with researchers outside of the participant's institution. Questions developed for determining a relationship between support and tenure/promotion requirements and between support and faculty satisfaction and self-perceptions were established from previous research.

To organize the survey, three sections were created: demographics, institutional support and resources, and faculty perceptions (see the Appendix for the survey in its entirety). The demographic data (questions 2-17) gathered characteristics of responders, including faculty position, type of institution, gender, and race. It also gathered data to determine the relevant publication and collaboration requirements needed for the participant to receive tenure and promotion at his or her institution.

The institutional support and resources section (questions 18-19) contained questions related to the amount and type of support received by individual faculty, including travel resources, physical space and equipment, and other incentives such as faculty release policies, summer stipends, and staff support. This provided data relevant to exploring primarily the first research question.

The perceptions section (questions 20-23) was designed to explore the remaining two research questions to (1) determine if computer science faculty believe that the institutional resources and support they receive for research is congruent with their requirements for tenure/promotion and (2) determine if a relationship exists between the amount of institutional resources and support and research productivity, collaboration (internal, external, and student), faculty satisfaction, faculty position, and tenure and promotion. This section included Likert-rated questions related to job satisfaction, job stress, and the alignment of institutional resources to their requirements for tenure and/or promotion.

Participants for the study included computing faculty in the departments of institutions appearing on the Forsythe list provided by the CRA, which contains a list of universities invited to participate in the 2008-09 Taulbee Survey. Though the Taulbee Survey participants were department chairs at computing departments, the population for our study included all full-time faculty within the departments at these institutions. The researchers obtained the email addresses of computing faculty at these institutions from researching publicly available on-line information. We chose to include the entire population in this study instead of a subset in order to ensure higher external validity.

Data was collected electronically and confidentially. Both researchers' committees on research of human subjects approved the data collection method. To gather data, an electronic form of the 
survey instrument was created on surveymonkey.com using SSL for an added measure of security. Data was limited to participants who agreed to the letter of consent that appeared on the first page. The survey was available to participants for two weeks, opening on February 28, 2011 and closing on March 16, 2011. Two emails were sent to the entire population for this study, 7,787 computing faculty at Forsythe Institutions in the United States and Canada. The first email announced the survey and invited participation. The second email was sent one week after the first to remind computing faculty of the survey closing date.

Upon the survey closing date, the data was downloaded from the online site and then analyzed using the SPSS software system. Descriptive statistics (frequency counts, means, ranges, and standard deviation) were used to analyze demographic data and data related to the first research question. Descriptive statistics were chosen since the data represents the diversity and rank among the respondents as well as the means of activities required for promotion. To explore the second and third research questions, Pearson correlation coefficients were used to evaluate a priori hypothesis established to determine if relationships existed between the amount of institutional resources and support and the following variables: number of publications and presentations, collaboration (internal and external), faculty position, faculty satisfaction, and tenure and promotion.

During a preliminary evaluation of the data, several outliers were discovered in free form numerical entry fields. For example, one respondent stated that he or she received $\$ 300,000$ for attending professional meetings in the 2009-10 academic year, an amount that we found inexplicable. Since extreme outliers can skew the data, we used the SPSS box plot method to identify extreme outliers in all free-form numerical entries, including the data for number of publications, number of presentations, and amounts of institutional support (Walfish, 2006). Only four extreme outliers were found and these entries were removed in order to reduce skewness.

In addition to including the entire population in the study, several additional steps have been taken to ensure internal and external validity and to address reliability. First, the methodology established for the study was rigorous and follows methodology defined by Creswell (2008) and used throughout similar studies referenced in the literature review. Second, the data analysis was thorough and included an analysis of a priori hypothesis directly related to the research questions. Third, significance of results were measured at the $\mathrm{p}<0.05$ level for all correlation measurements. Finally, to measure internal consistency, Cronbach's alpha was calculated for Likert-scale items related to faculty satisfaction and perceptions, both of which are key components to this entire study. Results are discussed in the next section.

\section{Results}

Since the study is meant to complement the Taulbee Survey data, the demographics for race, gender, faculty rank, and institution were set up similarly. For U.S. institutions, respondents could choose Computer Science (CS), Computer Engineering (CE), or U.S. Information departments. Those in the CS department could then further qualify their institution ranking as 1-12, 13-24, 2536 or other based on the name of their school and how it corresponded to the Taulbee survey. For simplicity, respondents selected the grouping in which their institution's name appeared (see question 9 in the Appendix).

The request for participation was sent to 7,787 computing faculty at the 256 Forsythe institutions who participate in the Taulbee Survey. Some surveys were unknowingly sent to part-time faculty, researchers, deans, emeriti faculty, and others. Some emails were returned undelivered, indicating that the email address was incorrect or the account had been closed.

The authors estimate the actual population for this study was 7,500. 447 valid surveys (6\% response rate) were submitted online, giving a confidence level of $95 \%$ with a $4.5 \%$ confidence in- 
terval (margin of error). All questions were answered voluntarily and some respondents did not answer all of the questions. Since only two respondents from Singapore responded, their results are not included in this analysis. Additionally, all surveys that were started and that had no data entered for the survey were removed.

Respondent demographic data is provided in the first section. This provides context for the data. The second section defines data related to the first research question and reviews the tenure and promotion requirements for respondents. The third section relates to the second research question examines institutional resources and support. Finally, the last section examines faculty satisfaction and perceptions about funding and research productivity, key points of the last two research questions. The entirety of the data and how it relates to the research questions is provided in the Discussion section.

\section{Participant Demographic Data}

To provide context for the data, the demographic data is presented using frequency counts and percentages. Of the 447 responses, there were 343 participants from CS departments in the U.S., 15 participants from CE departments in the U.S., 37 from Information departments in the U.S., and 52 participants from computing departments in Canada. Table 1 provides more detail.

\section{Table 1: Number of respondents per institution type}

\begin{tabular}{|l|r|r|}
\hline \multicolumn{1}{|c|}{ Institution/Department } & \multicolumn{1}{c|}{ Count } & \multicolumn{1}{c|}{$\%$} \\
\hline U.S. CS 1-12 & 28 & $6 \%$ \\
\hline U.S. CS 13-24 & 39 & $9 \%$ \\
\hline U.S. CS 25-36 & 39 & $9 \%$ \\
\hline U.S. CS Other & 237 & $53 \%$ \\
\hline U.S. CS Subtotal & 343 & $77 \%$ \\
\hline U.S. CE & 15 & $3 \%$ \\
\hline U.S. Information & 37 & $8 \%$ \\
\hline Canadian & 52 & $12 \%$ \\
\hline Total & 447 & \\
\hline
\end{tabular}

Faculty rank was also gathered using the Taulbee survey categories. 383 respondents specified their faculty rank, as shown in Table 2 . Similarly, 356 respondents specified their tenure status, with 70 responding that they did not have tenure and 286 responding that they did. For the remainder of the data analysis, data is only reported for those holding one of the professorial ranks $(n=356)$, giving a confidence level of $95 \%$ with a $5.2 \%$ confidence interval.

Table 2: Faculty rank of respondents

\begin{tabular}{|l|r|r|}
\hline \multicolumn{1}{|c|}{ Faculty Rank } & Count & \multicolumn{1}{c|}{$\%$} \\
\hline Full Professor & 156 & $43.8 \%$ \\
\hline Associate Professor & 130 & $36.5 \%$ \\
\hline Assistant Professor & 70 & $19.7 \%$ \\
Total & 356 & \\
\hline
\end{tabular}


336 of the professorial rank respondents gave their race, with 264 (78\%) identifying themselves as white and 76 (22\%) as non-white. 350 respondents provided their gender, with 286 (82\%) identifying themselves as male and the remaining 64 (18\%) as female.

\section{Tenure and Promotion Requirements}

The data (shown in Table 3) indicates that the number of publications required per academic year for tenure or promotion was on average $3.16(N=241, S D=1.60)$. During the entire probationary period for tenure, the average number of publications required was $12.90(N=180, S D=7.44)$, while the average number of publications required during the promotion review period was 17.09 $(N=167, S D=9.98)$.

\begin{tabular}{|l|r|r|r|}
\hline \multicolumn{4}{|c|}{ Table 3: Number of required publications } \\
\hline \multicolumn{1}{|c|}{ Publications } & \multicolumn{1}{|c|}{$\boldsymbol{N}$} & \multicolumn{1}{c|}{ Mean } & \multicolumn{1}{c|}{ SD } \\
\hline Per academic year & 241 & 3.16 & 1.60 \\
\hline During probationary period & 180 & 12.90 & 7.44 \\
\hline During promotion review period & 167 & 17.09 & 9.98 \\
\hline
\end{tabular}

Table 4: Importance of publication characteristics

\begin{tabular}{|l|r|r|r|}
\hline \multicolumn{1}{|c|}{ Publication Characteristics } & \multicolumn{1}{c|}{$\boldsymbol{N}$} & \multicolumn{1}{c|}{ Mean } & \multicolumn{1}{c|}{ SD } \\
\hline Refereed journals & 349 & 4.50 & 0.80 \\
\hline Refereed conferences & 350 & 4.17 & 0.92 \\
\hline Venue ranking & 348 & 3.93 & 0.98 \\
\hline Quantity of publications & 350 & 3.85 & 0.94 \\
\hline Acceptance rate & 350 & 3.70 & 0.98 \\
\hline Venue scope & 347 & 3.49 & 1.06 \\
\hline Non-refereed conferences & 346 & 1.90 & 0.71 \\
\hline Non-refereed journals & 333 & 1.87 & 0.71 \\
\hline
\end{tabular}

Respondents rated the characteristics of the publications on a 5-point Likert scale with the following scaling options (Table 4): 1-Unimportant, 2-Of Little Importance, 3-Moderately Important, 4Important, and 5-Very Important. Based on this, respondents stated that the most important publication characteristics were refereed journals $(M=4.5, S D=0.80)$ and refereed conferences $(M=4.17, S D=0.92)$. Venue ranking, number of publications, venue acceptance rate, and venue scope were also deemed important. Of little or no importance was non-referred conferences $(M=1.90, S D=0.71)$ and journals $(M=1.87, S D=0.71)$.

An open response box was also available for participants to note other requirements. Books and book chapters were noted the most, with 10 responses. Software and patents were noted a couple of times each. Other acceptable forms of activity noted once each included refereed magazines, funding, citation count, reference letters, refereed or invited presentations, content and contributions, editorial boards, conference program committees, professional associations, and refereed workshops. A couple of participants noted favoritism, including one who noted that "(e)xcept for certain people loved by the Dean, only peer-reviewed counts. For the Dean's pet, everything counts." 
Over 70\% of institutions formally require (in written policy) external collaboration activities and $65 \%$ require internal collaboration activities for tenure and promotion. Another $25.6 \%$ and $30.9 \%$ of institutions expect collaboration externally and internally, respectively, though it is part of the department culture rather than written policy.

The type of collaborative activity required is not fully specified by the respondents. Collaborative publications and grants garnered the highest responses, but mostly at the informally required level. Presentations and projects are also ranked very high at the informally required level. Table 5 summarizes the results.

There was a wide range of responses for the number of publications and presentations given during the 2009-10 academic year (Table 6). The number of presentations ranged from 0 to 36, though the mean was $3.3(S D=3.78)$. For the number of publications, the range was $0-19$ and the mean was $5.44(S D=3.89)$.

Table 5: Collaborative activities

\begin{tabular}{|l|r|r|r|r|r|r|}
\hline \multirow{2}{*}{ Type } & \multicolumn{2}{|c|}{$\begin{array}{c}\text { Formally Required } \\
\text { (Written Policy) }\end{array}$} & \multicolumn{2}{|c|}{$\begin{array}{c}\text { Informally Required } \\
\text { (Culture/Environment) }\end{array}$} & \multicolumn{2}{c|}{ Not Required } \\
\cline { 2 - 7 } & \multicolumn{1}{|c|}{ Count } & $\%$ & Count & $\%$ & Count & $\%$ \\
\hline External & 243 & $70.6 \%$ & 88 & $25.6 \%$ & 13 & $3.8 \%$ \\
\hline Internal & 225 & $65.0 \%$ & 107 & $30.9 \%$ & 14 & $4.0 \%$ \\
\hline Publications & 103 & $29.8 \%$ & 119 & $34.4 \%$ & 124 & $35.8 \%$ \\
\hline Grants & 48 & $13.8 \%$ & 133 & $38.3 \%$ & 166 & $47.8 \%$ \\
\hline Presentations & 28 & $7.9 \%$ & 198 & $57.4 \%$ & 119 & $34.5 \%$ \\
\hline Projects & 14 & $4.1 \%$ & 209 & $61.3 \%$ & 118 & $34.6 \%$ \\
\hline
\end{tabular}

Table 6: Number of presentations and publications for 2009-10

\begin{tabular}{|l|r|r|r|}
\hline \multicolumn{1}{|c|}{ Type } & \multicolumn{1}{c|}{ N } & \multicolumn{1}{c|}{ Mean } & \multicolumn{1}{c|}{ SD } \\
\hline Presentations & 241 & 3.16 & 1.60 \\
\hline Publications & 167 & 17.09 & 9.98 \\
\hline
\end{tabular}

\section{Resources and Tenure and Promotion Requirements}

This section summarizes the data for faculty resources and support and compares this against the number of publications and presentations required, collaboration (internal and external), faculty position, and tenure and promotion factors.

\section{Resources and support}

Of the 247 respondents who provided estimated amounts of institutional support they have received, over \$2.7 million went to computer purchases or upgrades (Table 7). Staff support and research lab upgrades were also provided to faculty with over \$1 million in support for all of the respondents, though several mentioned in an open response box that they shared staff support with others and were unable to place an estimated amount in that category. In the open response box, respondents also noted that some other categories were also difficult to place an estimated amount on, including mentorship, promotion and tenure seminars, flexibility about tenure clock, 
and tuition remission. Though several of these categories appear as the smallest form of institutional support, the number of respondents who claimed to receive such support was significant.

Several participants gave feedback in the open response form for type of institutional support. Items noted include support for professional development, partial travel reimbursement, startup/discretionary spending, funds to visit other institutions, graduate student support, research assistants, teaching assistants, and computer support.

In the academic year 2009-10, only $13.2 \%$ of institutions saw an increase in the level of institutional support and resources from the previous year (Table 8). The remaining institutions either saw their level of support stay the same (58.9\%) or decrease $(28 \%)$.

\begin{tabular}{|l|r|r|r|r|r|}
\hline \multicolumn{7}{|c|}{ Table 7: Amount and type of institutional support } \\
\hline \multicolumn{1}{|c|}{ Type } & \multicolumn{1}{|c|}{$\boldsymbol{N}$} & \multicolumn{1}{c|}{$\%$} & \multicolumn{1}{c|}{ Sum } & \multicolumn{1}{c|}{$\boldsymbol{M}$} & \multicolumn{1}{c|}{ SD } \\
\hline Computer Purchase Or Upgrade & 177 & 71.7 & $\$ 2,727,977$ & 15,417 & 150,662 \\
\hline Staff Support & 125 & 50.6 & $\$ 1,315,711$ & 10,525 & 26,072 \\
\hline Research Lab Upgrades & 105 & 42.5 & $\$ 1,150,301$ & 10,955 & 97,760 \\
\hline Summer Salary & 128 & 51.8 & $\$ 971,530$ & 7,590 & 14,928 \\
\hline Stipend & 100 & 40.5 & $\$ 740,401$ & 7,404 & 24,864 \\
\hline Release Time & 108 & 43.7 & $\$ 515,101$ & 4,769 & 13,497 \\
\hline Improvements to Other Spaces & 114 & 46.2 & $\$ 403,701$ & 3,541 & 13,971 \\
\hline Conferences & 188 & 76.1 & $\$ 314,550$ & 1,682 & 4,255 \\
\hline Professional Meetings & 145 & 58.7 & $\$ 123,851$ & 854 & 2,067 \\
\hline Improvements to Office Space or Facilities & 113 & 45.7 & $\$ 162,201$ & 1,435 & 4,933 \\
\hline Tuition Remission & 92 & 37.2 & $\$ 54,301$ & 590 & 3,766 \\
\hline Mentorship & 97 & 39.3 & $\$ 34,503$ & 355 & 1,701 \\
\hline Grant Writing Support Or Seminars & 96 & 38.9 & $\$ 16,776$ & 174 & 1,053 \\
\hline Workshops Or Training & 94 & 38.1 & $\$ 12,104$ & 128 & 468 \\
\hline Promotion And Tenure Seminars & 92 & 37.2 & $\$ 6,602$ & 71 & 389 \\
\hline Flexibility About Tenure Clock & 85 & 34.4 & $\$ 101$ & 1 & 10 \\
\hline Total & 247 & & $\$ 8,549,711$ & $\$ 34,614$ & \\
\hline
\end{tabular}

\begin{tabular}{|l|r|l|}
\hline \multicolumn{3}{|c|}{ Table 8: Change in support levels 2009-10 } \\
\hline \multicolumn{1}{|c|}{ Level of support } & Count & \multicolumn{1}{c|}{$\%$} \\
\hline Increase from previous year & 40 & $13.2 \%$ \\
\hline Stayed the same as previous year & 179 & $58.9 \%$ \\
\hline Decreased from previous year & 85 & $28.0 \%$ \\
\hline
\end{tabular}

Of the 318 participants who answered the support questions, $75 \%$ of faculty stated that they received funding from any source for conferences during the 2009-10 academic year (Table 9). Conference funding was by far the leading type of support received. Nearly $65 \%$ also stated that they received funding for computer purchases or upgrades. Over half also stated that they receive 
support in the form of summer salaries, attendance at professional meetings, and staff support. The level of support from any source dramatically reduces in the remaining categories. Table 9 presents both the percentage of respondents who gave responses either indicating that they received support from any source or solely from their institution.

In addition to the list of categories provided in the survey, faculty also noted additional types of support provided by any source: professional development, start-up funding (\$250,000 in one case), funds for research from international organizations, books, equipment, funds to visit other institutions, teaching assistants, release time for administrative duties, academic senate awards, and graduate student support. Not all respondents received institutional support. One participant noted that "Everything on your list comes out of my grant funds or I do without."

\begin{tabular}{|l|r|r|r|r|}
\hline \multicolumn{1}{|c|}{ Table 9: Support from any sources, including institutional support } \\
\hline \multirow{2}{*}{ Type (N=356) } & \multicolumn{1}{|c|}{ Any support } & \multicolumn{1}{|c|}{ Institutional support } \\
\cline { 2 - 5 } & Count & \multicolumn{1}{|c|}{$\%$} & Count & \multicolumn{1}{|c|}{$\%$} \\
\hline Being funded to attend conferences & 267 & 75.0 & 188 & 52.8 \\
\hline Computer Purchase Or Upgrade & 231 & 64.9 & 177 & 49.7 \\
\hline Summer Salary & 194 & 54.5 & 128 & 36.0 \\
\hline Being funded to attend professional meetings & 186 & 52.2 & 145 & 40.7 \\
\hline Staff Support & 181 & 50.8 & 125 & 35.1 \\
\hline Release Time & 72 & 20.2 & 108 & 30.3 \\
\hline Research Lab Upgrades & 68 & 19.1 & 105 & 29.5 \\
\hline Grant Writing Support or seminars & 68 & 19.1 & 96 & 27.0 \\
\hline Improvements to other spaces & 65 & 18.3 & 114 & 32.0 \\
\hline Improvements to office space or facilities & 55 & 15.4 & 113 & 31.7 \\
\hline Mentorship & 55 & 15.4 & 97 & 27.2 \\
\hline Stipend & 53 & 14.9 & 100 & 28.1 \\
\hline Promotion and tenure seminars & 49 & 13.8 & 92 & 25.8 \\
\hline Workshops or training & 44 & 12.4 & 94 & 26.4 \\
\hline Flexibility about tenure clock & 15 & 4.2 & 85 & 23.9 \\
\hline Tuition remission for you & 7 & 2.0 & 92 & 25.8 \\
\hline
\end{tabular}

\section{Support and quantity of publications and presentations}

Pearson correlation coefficients (r) were used to determine if there was a relationship between the amount of institutional resources and support and number of publications and presentations, collaboration (internal and external), faculty position, and tenure and promotion. Institutional resources and support was measured by adding the numeric responses entered for all 16 categories. Though significant coefficients identified several correlations, no cause-effect relationship can be assumed.

Correlation coefficients were computed among the amount of funding received from the institution and the sum of the number of publications and presentations given in the previous year. It 
was found that a significant, but weak, relationship exists between funding and the number of publications and presentations $(r=.13, p=.04, N=247)$.

When compared against each individual funding item, two significant relationships were found. A positive relationship was found between the items Computer Purchase or Upgrade and the number of publications and presentations given $(r=.19, p=.01, N=176)$ and Research lab upgrades $(r=0.22, p=0.03, N=104)$.

\section{Faculty Perceptions and Satisfaction}

Beyond gathering data about tenure and promotion requirements and funding, the researchers sought the perceptions and level of satisfaction among respondents. Participants were asked to rate their agreement with each item shown in Tables 10 and 11 using the following Likert scale: Not applicable, Strongly disagree, Disagree, Undecided, Agree, Strongly Agree. As noted in Section 3, questions were derived from similar published research of faculty satisfaction and perceptions in the fields of social work and geography (Freedenthal et al., 2008; Solem \& Foote, 2004).

To measure internal consistency across items in the satisfaction and perception categories, Cronbach's alpha was calculated for the 14 satisfaction and perception items (Table 10) and the 16 satisfaction items (Table 11) and were 0.98 and 0.95, respectively.

\begin{tabular}{|c|c|c|c|}
\hline \multicolumn{4}{|l|}{ Table 10: Faculty satisfaction and perceptions } \\
\hline Item & $N$ & $M$ & $S D$ \\
\hline I take research and scholarship seriously. & 311 & 4.61 & 0.55 \\
\hline $\begin{array}{l}\text { As part of my position, I am expected to seek external grants funds to fund my re- } \\
\text { search. }\end{array}$ & 307 & 4.44 & 0.92 \\
\hline My research has a good reputation in my discipline. & 312 & 4.14 & 0.80 \\
\hline My research has attracted interest from my peers. & 306 & 4.10 & 0.74 \\
\hline I am a very productive researcher. & 311 & 3.91 & 1.01 \\
\hline My department/home unit values my research. & 311 & 3.82 & 1.06 \\
\hline I am satisfied with the recognition I receive from my peers in my discipline. & 306 & 3.77 & 0.82 \\
\hline I am satisfied with my opportunities for research collaboration. & 309 & 3.76 & 0.95 \\
\hline I am satisfied with my opportunities for networking in my discipline. & 308 & 3.73 & 0.91 \\
\hline Mentoring by research peers is important to me. & 290 & 3.66 & 0.89 \\
\hline Mentoring by research peers has improved the quality of my research/publications. & 287 & 3.49 & 1.01 \\
\hline My institution offers adequate resources for faculty. & 310 & 3.30 & 1.19 \\
\hline Mentoring by research peers has improved the quantity of my research/publications. & 286 & 3.14 & 1.06 \\
\hline The tenure and promotion process causes me an unreasonable amount of stress. & 271 & 2.89 & 1.31 \\
\hline
\end{tabular}




\begin{tabular}{|l|c|c|c|}
\hline \multicolumn{4}{|c|}{ Table 11: Faculty satisfaction with institutional resources and support } \\
\hline \multicolumn{1}{|c|}{ Satisfied with Institutional Resources and Support for: } & $\boldsymbol{M}$ & $\boldsymbol{M} \boldsymbol{D}$ \\
\hline Computer purchases or upgrade & 290 & 3.21 & 1.23 \\
\hline Flexibility about the tenure clock & 193 & 3.17 & 1.02 \\
\hline Grant writing support or seminars & 253 & 3.11 & 1.09 \\
\hline Workshops or training & 221 & 3.09 & 1.07 \\
\hline Promotion and tenure seminars & 220 & 3.02 & 1.09 \\
\hline Being funded to attend conferences & 274 & 3.01 & 1.25 \\
\hline Improvements to office space or facilities & 281 & 2.99 & 1.18 \\
\hline Tuition remission for you & 165 & 2.99 & 1.16 \\
\hline Improvements to other space(s) (research lab, studio space, etc.) & 271 & 2.96 & 1.20 \\
\hline Staff support (research assistants, clerical, other) & 285 & 2.95 & 1.26 \\
\hline Being funded to attend professional meetings & 260 & 2.91 & 1.26 \\
\hline Summer salary & 234 & 2.79 & 1.26 \\
\hline Mentorship (informal or formal) & 246 & 2.78 & 1.19 \\
\hline Release time & 248 & 2.77 & 1.27 \\
\hline Research lab upgrades & 260 & 2.74 & 1.15 \\
\hline Stipends & 213 & 2.60 & 1.19 \\
\hline
\end{tabular}

The final survey question asked participants to select up to three areas in which "if your institutional support increased, your research productivity would increase." The top three areas identified were funding for support staff, funding for release time, and funding for attending conferences. Table 12 shows the results.

In addition, several participants noted that receiving additional institutional support in the forms of research and teaching assistants would enable them to increase their research productivity. Several participants noted that assistants should be of high "quality" and funding for recruiting assistants would be helpful, including student scholarships. Numerous other support items were cited, including reduced teaching loads, flexibility in teaching schedule, release from administrative duties, less bureaucracy, helpful administration, clarification of school mission, and "secretaries that are much more computer-savvy (TeX, html, website construction...)."

Several additional comments were made about direct support for research, including support for research equipment and engineering support, streamlined pre- and post-award support, reallocation of responsibilities (teaching loads) between more research-active faculty and less researchactive faculty, and office supplies and other resources that are shared across research projects. One participant noted support in the form of "appreciation of original, inspired and courageous research, provided it has solid foundations, even if it is risky and not immediately popular." Another noted support in the form of appreciation of "the importance of diversity of research interests and styles of individual research."

A couple of participants noted that a "fair and objective reward structure" and "being ethically and professionally evaluated" would enable them to increase their research productivity. Another noted that "recognition of quality issues" would enable their research, but this was not clarified. Finally, one participant noted cultural climate support, including free and unlimited coffee and refreshments. 


\begin{tabular}{|l|l|}
\hline \multicolumn{2}{|c|}{ Table 12: Institutional support for increasing faculty productivity } \\
\hline \multicolumn{1}{|c|}{ Type } & Count \\
\hline Staff support (research assistants, clerical, other) & 129 \\
\hline Release Time & 120 \\
\hline Being funded to attend conferences & 88 \\
\hline Office Other & 49 \\
\hline Summer salary & 46 \\
\hline Computer purchase or upgrade & 43 \\
\hline Research Lab Upgrade & 43 \\
\hline Grant Writing Support & 40 \\
\hline Professional Meetings & 34 \\
\hline Office Space Facilities & 34 \\
\hline Mentorship (informal or formal) & 31 \\
\hline Stipends & 16 \\
\hline Flexibility about the tenure clock & 4 \\
\hline Promotion and tenure seminars & 4 \\
\hline
\end{tabular}

\section{Support and tenure/promotion requirements}

Several a priori hypotheses for the survey items were designed to investigate the relationship between the institutional resources and support and the tenure and promotion requirements. Relationships were also examined between institutional resources and support and perceptions and satisfaction levels.

The first hypothesis stated there is a relationship between the level of institutional support and computer science faculty who think their institution offers adequate resources for faculty. The hypothesis was analyzed with Pearson's correlation coefficient. The assumption was that there may be an inverse relationship between the two and that those not receiving much funding would also be more likely to agree that their institution did not offer adequate resources. To analyze this, the responses for the perception item "My institution offers adequate resources for faculty" was compared against the sum of institutional resources and support. No significant relationship was found between the two ( $\mathrm{r}=-.08, p=0.20, N=234)$.

Another hypothesis examined whether there was a relationship between level of institutional support and tenure/promotion requirements. This was investigated to see if faculty with more demanding requirements also received additional institutional support. To analyze this, several subhypotheses were examined. The first sub-hypothesis investigated if there was a relationship between level of institutional support for conferences and the emphasis placed on refereed conferences. No significant relationship was found ( $\mathrm{r}=-.04, \mathrm{p}=.57, N=186)$.

Another sub-hypothesis examined whether there was a relationship between expectations to seek external grants and (1) institutional funding for release time and (2) institutional funding for grant writing support or seminars. A significant relationship was found between grant expectations and institutional funding for release time ( $\mathrm{r}=-.20, p=.04, N=104)$. No significant relationship was found between grant funding expectations and institutional funding for grant writing support or seminars $(\mathrm{r}=.07, p=.52, N=92)$. 


\section{Support and collaboration}

Similarly, an analysis was performed on institutional support and the responses to questions on the survey involving collaboration. Each of the six collaboration activities (that were formally or informally required) was compared against the statement "I am satisfied with my opportunities for research collaboration." No significant relationships were found. Each of the activities were then compared against the statement "I am satisfied with my opportunities for networking in my discipline." Again, no significant relationships found.

Each of the six collaboration activities were then compared against the total amount of funding participants received from their institutions. Three significant relationships found, listed in order of strength of their relationship:

- External collaborations $(r=0.22, p=0.00, N=241)$

- Internal collaborations ( $\mathrm{r}=0.21, p=0.00, N=242)$

- Project collaboration ( $\mathrm{r}=-0.15, p=0.02, N=242$ )

The results indicate that there is a positive correlation between external and internal collaboration requirements for tenure and promotion and the amount of institutional funding received by participants. However, there is an inverse relationship (albeit weak) between participants who are required (informally or formally) to participate in project collaboration activities and the amount of funding received. Faculty who receive more institutional funding are more likely to engage in internal and external collaboration, while those who receive less institutional funding are more likely to engage in project collaborations.

\section{Support and faculty satisfaction}

An analysis was performed to determine if there is a relationship between the responses to "The tenure and promotion process causes me an unreasonable amount of stress" and each of the other satisfaction and perception variables (Table 13). Seven significant relationships were found.

In order of the strength of the relationship, those who agreed that the tenure and promotion process causes them stress:

- Do not agree that their institution offers adequate resources for faculty $(r=-0.26, p=0.00$, $\mathrm{n}=270$ ),

- Do not agree that their department/home unit values their research $(r=-0.25, p=0.00$, $n=269$ ),

- Agree that mentoring has improved the quantity (but not quality) of their research/publications ( $r=0.19, p=0.00, \mathrm{n}=255)$,

- Agree that mentoring by research peers is important to them $(r=0.17, p=0.01, \mathrm{n}=262)$,

- Are not satisfied with the recognition they receive from peers in their discipline $(r=-0.14$, $p=0.02, \mathrm{n}=267)$,

- Are not satisfied with their opportunities for networking in their discipline ( $r=-0.14$, $p=0.02, \mathrm{n}=267$ ), and

- Are not satisfied with their opportunities for research collaboration $(r=-0.13, p=0.04$, $\mathrm{n}=269)$.

Significant relationships were also found between those who agreed that the tenure and promotion process causes them stress and their satisfaction with the support provided by their institutions along a variety of items (Table 14). In fact, the only non-significant relationship found was between the level of stress and the amount of support received for tuition remission. The most significant inverse relationships $(\mathrm{r}<-0.20)$, in order of strength of the relationship, were stipends, summer salary, release time, funding to attend professional meetings, funding to attend confer- 
ences, promotion and tenure seminars, workshops or training, and grant-writing support or seminars.

Table 13: Correlations between stress and related variables

\begin{tabular}{|c|c|c|c|}
\hline Level of stress in relationship to: & $N$ & $r$ & $p$ \\
\hline I take research and scholarship seriously. & 270 & -0.07 & 0.29 \\
\hline $\begin{array}{l}\text { As part of my position, I am expected to seek external grants funds to fund my } \\
\text { research. }\end{array}$ & 267 & 0.03 & 0.61 \\
\hline My research has a good reputation in my discipline. & 270 & -0.02 & 0.75 \\
\hline My research has attracted interest from my peers. & 268 & -0.06 & 0.30 \\
\hline I am a very productive researcher. & 270 & -0.01 & 0.91 \\
\hline My department/home unit values my research. & 269 & -0.25 & 0.00 \\
\hline I am satisfied with the recognition I receive from my peers in my discipline. & 267 & -0.14 & 0.02 \\
\hline I am satisfied with my opportunities for research collaboration. & 269 & -0.13 & 0.04 \\
\hline I am satisfied with my opportunities for networking in my discipline. & 269 & -0.14 & 0.02 \\
\hline Mentoring by research peers is important to me. & 262 & 0.17 & 0.01 \\
\hline $\begin{array}{l}\text { Mentoring by research peers has improved the quality of my re- } \\
\text { search/publications. }\end{array}$ & 256 & 0.07 & 0.24 \\
\hline My institution offers adequate resources for faculty. & 270 & -0.26 & 0.00 \\
\hline $\begin{array}{l}\text { Mentoring by research peers has improved the quantity of my re- } \\
\text { search/publications. }\end{array}$ & 255 & 0.19 & 0.00 \\
\hline
\end{tabular}

Table 14: Stress and dissatisfaction levels with various types of institutional support

\begin{tabular}{|l|c|c|c|}
\hline \multicolumn{1}{|c|}{ Type of support } & $\boldsymbol{N}$ & $\boldsymbol{r}$ & $\boldsymbol{p}$ \\
\hline Stipends & 188 & -0.34 & 0.00 \\
\hline Summar salary & 209 & -0.31 & 0.00 \\
\hline Release time & 218 & -0.30 & 0.00 \\
\hline Being funded to attend professional meetings & 228 & -0.25 & 0.00 \\
\hline Being funded to attend conferences & 236 & -0.23 & 0.00 \\
\hline Promotions and tenure seminars & 206 & -0.23 & 0.00 \\
\hline Workshops or training & 200 & -0.23 & 0.00 \\
\hline Grant writing support or seminars & 225 & -0.22 & 0.00 \\
\hline Mentorship (informal or formal) & 224 & -0.19 & 0.01 \\
\hline Staff support (research assistants, clerical, other) & 248 & -0.18 & 0.01 \\
\hline Research lab upgrades & 227 & -0.16 & 0.02 \\
\hline Improvements to other space(s) (research lab, studio spaces, etc.) & 236 & -0.15 & 0.03 \\
\hline Computer purchase or upgrade & 249 & -0.15 & 0.02 \\
\hline Improvements to office space or facilities & 243 & -0.12 & 0.05 \\
\hline Tuition remission to you & 148 & -0.11 & 0.19 \\
\hline
\end{tabular}




\section{Support and faculty position}

Relationships were examined between each type of institutional support received by respondents and their faculty rank. Relationships were also examined between the entire sum of institutional support received by respondents and their faculty rank. No significant relationships were found.

\section{Support and tenure}

Relationships were examined between each type of institutional support received by respondents and tenure status (tenured or not tenured). Relationships were also examined between the entire sum of institutional support received by respondents and their faculty rank. Though no significant relationship was found between the entire sum of support and tenure status, there were several significant relationships found between tenure status and three individual funding items.

There was a relationship found between tenure status and the amount of funding received for each of the following items:

- $\quad$ Staff support $(r=-0.27, p=0.00, N=125)$;

- Summer salary $(r=-0.22, p=0.01, N=128)$;

- Workshops and training ( $r=-0.22, p=0.03, N=94)$; and

- Improvements to office space or facilities $(r=-0.19, p=0.046, N=113)$.

Faculty with tenure were more likely to receive more funding for each of these items than untenured faculty.

\section{Analysis}

Three research questions were originally posed at the start of this research. In this section, the demographic and background data is explored to establish baseline information about tenure and promotion requirements. The remaining data is then explored in the context of the three research questions.

\section{Demographic and Background Data}

To provide context for this study, basic demographic data was collected and indicates that the survey was completed by a wide variety of faculty. Professorial faculty at a variety of Forsythe institutions participated. Faculty of various races participated, and both men and women participated at significant levels. Based on the number of respondents and their demographic information, we propose that the data is representative of computing faculty at the Forsythe institutions and can be generalized (Harris, 1997).

The results also indicate that, on average, computing faculty are required to publish three articles per academic year for tenure and promotion. In the academic year 2009-10, faculty appear to have met this requirement, with an average of approximately 5 publications (any type) and approximately 3 presentations (any type). The average of number of publications required for the entire tenure period is approximately 13 and for the promotion review period is approximately 17. The standard deviation for the averages was high, indicating variability in this requirement among institutions.

The most important venues of research productivity based on the survey responses were refereed journals and conferences. The ranking of the venue, quantity of publications, and acceptance rate were important as well, but at a lesser level. Books and book chapters were frequently mentioned in the free response box. Refereed magazines, refereed workshops, refereed presentations, citation count, and professional activities were also mentioned as important. Non-refereed conferences and journals were of little importance. 
Collaborative activities are required for nearly all faculty (96\%), with great emphasis placed on both external and internal collaborations. About two-thirds note that specific types of collaborative activities are required, including publications, presentations, projects and grants. Unfortunately over $25 \%$ of faculty believe that these activities are not formally required by tenure and promotion requirements, but rather are informally required by the culture/environment. In fact, over half of faculty (61\%) believe that collaborative projects are informally required for tenure and promotion and not part of written policy. We have deemed these "hidden requirements", since they are not explicitly stated. Faculty must learn the culture of their department before working to meet them. This may place faculty, especially new faculty or faculty who are not heavily integrated into the department culture (even possibly due to factors such as race, gender, or ethnicity), at a disadvantage.

It is worth noting that in the 2009-10 academic year, only 13\% of faculty saw an increase in their level of support from the previous year. While the majority (nearly 59\%) saw their support remain the same as the previous year, 28\% saw a decrease in their support, possibly reflecting the current economic climate.

The remaining data is analyzed in context of the remaining research questions. The first section analyzes the type and amount of institutional resources and support faculty receive, followed by an analysis of the survey items that indicate whether faculty believe that institutional support is congruent with tenure and promotion requirements. The third section examines whether there is a relationship between institutional resources and support and several other variables, including research productivity, collaboration, faculty satisfaction, faculty position, and tenure and promotion status. It is important to note that no definitions were provided in these categories and the question as posed did not necessarily limit the participant to respond solely for the previous academic year.

\section{Types of Institutional Resources and Support}

The first research question, "What types of institutional resources and support for research do individual computer science faculty receive?" is addressed in the results. As indicated by the data, the type of institutional support noted by the majority of faculty (over 70\%) includes computer purchases or upgrades and funding for attending conferences. Funding for attending professional meetings, summer salary, and staff support (including research and teaching assistants) was noted by between $50-60 \%$ of the faculty. Between $40-50 \%$ of faculty received institutional support for improvements to office space of facilities, improvements to other spaces, release time, stipends and research lab upgrades. Between 30-40\% of faculty received support for tuition remission, mentorship, grant writing support or seminars, workshops or training, promotion and tenure seminars, and flexibility with their tenure clock. Fewer faculty noted support for professional development, travel, startup funds, funds to visit other institutions, computer support, and graduate student support.

\section{Support Congruence with Tenure and Promotion Requirements}

To answer the question "do individual computer science faculty believe that the institutional resources and support they receive is congruent with their requirements for tenure/promotion," several responses were examined. Overall, the data indicated that computing faculty were found to be slightly dissatisfied with the support levels provided by their institutions. When asked directly if they agreed that their institution provided adequate resources for faculty, responses were only slightly above neutral (slightly agree) $(M=3.3, S D=1.19)$. However, other indicators show more dissatisfaction. Faculty are slightly dissatisfied $(\mathrm{M}<2.85)$ with the level of institutional support for stipends, research lab upgrades, release time, mentorship (informal or formal), and summer salaries. Faculty also noted that they were neutral (neither satisfied nor dissatisfied, 
$2.85<\mathrm{M}<3.15$ ) with their funding levels to attend professional meetings and conferences, staff support, improvements to office and other spaces, tuition remission for them, promotion and tenure seminars, grant writing support or seminars and workshops or training. Faculty are only slightly satisfied ( $M>3.15)$ with the flexibility given to their tenure clock and their computer purchases or upgrades. For each of these, the standard deviation ranged from 1.02 to 1.27, indicating that there was a balance between faculty that were slightly satisfied with funding levels and those that were slightly dissatisfied.

Faculty clearly have an opinion as to what support might enable them to increase their research productivity. Staff support (including support for teaching and research assistants) and release time were the two areas in which faculty think that increased funding would increase their research productivity. Increased funding to attend conferences followed this. Much lower on the list was funding for upgrading spaces other than office (labs, etc), summer salaries, computer purchases or upgrades, research lab upgrades, and grant writing support, both pre- and post-award.

\section{Significant Relationships}

Several variables were examined to answer the third research question, "Is there a relationship between the amount of institutional resources and support and research productivity, collaboration (internal, external, and student), faculty satisfaction, faculty position, and tenure and promotion?" Three significant relationships were found between the level of institutional support and funding received and collaboration activities. Faculty who were expected to participate in internal and external collaborations (either formally or informally) also received a higher level of funding than those who were not. Faculty who were expected to participate in project collaborations received a lower level of funding than faculty who were not, though this relationship was weak.

Several significant relationships were found between faculty responses to "The tenure and promotion process causes me an unreasonable amount of stress" and levels of institutional support, all inverse relationships. Those who noted that the tenure and promotion process causes them undue stress agree that mentoring is important to them and that mentoring has improved the quantity (but not quality) of their research/publications. But they were less satisfied with the resources offered by their institution, less satisfied in the value of their research place by their department/home unit, less satisfied with the recognition they received from peers and opportunities for networking in their discipline, and less satisfied with their opportunities for research collaboration. Faculty who felt more stressed by the tenure and promotion process also were less satisfied with nearly all levels of support they received from their institution. The strongest correlations were found for stipends, summer salaries, release time, being funded to attend professional meetings and conferences, promotion and tenure seminars, workshops or training, and grant writing support or seminars $(r<-0.20)$.

One significant relationship was found between those faculty who are expected to seek external grants and institutional funding for release time. Faculty who are expected to seek external grants are less likely to have received funding for release time. But no relationship was found between faculty perceptions about funding support levels and the actual sum of support provided by the institution. This indicates that though some faculty receive more funding than others, this had no correlation with their satisfaction with the support they receive. In other words, the level of support received by faculty had no bearing on their perceptions of the adequacy of their level of institutional support.

Though one might assume that there would be a relationship between the level of support received for travel to conferences and the emphasis placed on publishing in proceedings of refereed conferences for faculty, no such relationship was found. No significant relationship was found between expectations of faculty to seek external grants and institutional funding for grant writing 
support or seminars. No significant relationships were found between faculty position (assistant, associate, or full professor) and level of support. There were, however, several significant relationships found between tenure status and level of institutional support. Untenured professors had significantly less staff support, less funding for summer salaries and workshops and training, and less funding for improvements to office space or facilities.

\section{Discussion}

Several significant findings can be concluded from this study. These results both make new contributions to the literature on promotion and tenure and faculty support and confirm some previous work. These are framed with respect to the three original research questions. This section also examines threats to validity and provides suggestions for future research.

\section{Significant Findings}

One of the most novel results of this work is the identification of hidden promotion and tenure requirements. This was discovered while exploring the second research question, "Do individual computer science faculty believe that the institutional resources and support they receive for research is congruent with their requirements for tenure/promotion?" In exploring this question, we found that collaborative activities were required of nearly all faculty, although these requirements were typically only informally defined and understood. While the importance of collaborative activities on faculty productivity have been noted in other studies (Shaw 2002), there are no other studies that found such a strong hidden promotion and tenure requirement. The importance of collaborative activities for computer science faculty has already been noted by the CRA (1999), and this study shows that these activities remain crucial. Like information systems and information technology (Athey \& Plotnicki, 2000; Dennis et al., 2006), there may be a gap between the formal requirements for promotion and tenure and the actual situation that computer science faculty face. This is particularly troubling in light of Xu's study (2008) that found for faculty in the applied and hard sciences structured guidelines and clear expectations for productivity in teaching, publishing, and community service may help reduce work stress and effectively lower faculty turnover.

Another important factor uncovered while exploring this research question is that both refereed journals and conferences are important factors in achieving tenure and promotion. This result supports guidelines by the CRA (1999), which maintains that conference publications are valuable since they provide a forum for dissemination of current research. It does somewhat counter a more recent article that found via a bibliometric study that computer science journal articles have a more significant impact than conference publications (Franceschet, 2010). The more recent view presented by Halpern and Parkes (2011) suggesting journals be used for certification and conferences for rapid dissemination for research fits with current tenure and promotion guidelines. The issue of publication venue for work in computer science remains open for debate.

One troubling result in light of previous work is that the level of support in the academic year 2009-10 was stagnant. This insight was uncovered while exploring the first research question, "What types of institutional resources and support for research do individual computer science faculty receive?" Previous studies have shown a positive relationship between faculty productivity and faculty support (Freedenthal et al., 2008; Gruppen et al., 2003; Thomas et al., 2004), a result that our work confirms. We found a positive correlation between internal and external collaboration and the amount of institutional funding that faculty receive. The more institutional funding a faculty member receives, the more likely that faculty member is to engage in internal and external collaboration, and vice versa. Given the importance of the hidden requirement for collaboration and the increasing cost of travel, a stagnant level of support could result in a decrease in faculty productivity, impacting faculty promotion, tenure, and retention. 
The final research question sought to determine if there is relationship between the amount of institutional resources and support and research productivity, collaboration (internal, external, and student), faculty satisfaction, faculty position, and tenure and promotion.

Another significant result of this work is the finding that faculty are not satisfied with their level of institutional support and don't think overall that funding is congruent with tenure and promotion requirements. They think that the three areas that would enable them to increase their research productivity are in the areas of staff support, including teaching and research assistants, release time, and funding for attending conferences. Given the relationships that previous researchers have found between faculty support and productivity discussed above, it would appear that problems with promotion and tenure requirements may not be limited to the information systems and information technology disciplines (Athey \& Plotnicki, 2000; Dennis et al., 2006). If faculty satisfaction with the alignment of support and funding remains low, it could exacerbate retention issues. This is highlighted by our result showing that faculty who feel stressed about the promotion and tenure process were less satisfied with nearly all levels of support they received from their institution. Institutions with faculty who are dissatisfied with the support they receive may suffer from retention problems, which is particularly troublesome for disciplines where recruitment is already an issue such as computing (Camp, 1997). Most troubling in light of this issue is that untenured faculty had less staff support, less funding for summer salaries and workshop and training, and less funding for improvements to office space or facilities than their tenured colleagues.

\section{Threats to Validity}

The population and selection process was comprehensive. All faculty at all 256 institutions were invited to participate in this study. However, a small percentage of these invitations did not reach the intended recipients, due to errors in the address, the email address no longer being active, and spam filters. Even so, the authors are confident that, given the variety of demographic information received, the data is representative of the faculty working at institutions on the Forsythe list.

The main internal threat, as defined by Stanley and Campbell (1963), is the instrumentation. This was the first full-scale use of the survey instrument and several issues arose, including two technical errors in the online form of the survey. Thirty responses were dismissed due to an error in the survey set-up that allowed participants to continue the survey without agreeing to the terms of the letter of consent. Additionally, one data entry field for capturing the annual teaching load of the participant did not permit entries with real numbers (1.5 courses, for example). Data capture for this item was subsequently removed and not reported in this study due to the inability for respondents to accurately specify their course load.

The authors relied primarily on previous research and secondarily on their own experiences with tenure and promotion requirements for developing the survey items. Reliability of the survey instrument was limited to measuring the internal consistency within two important questions using Cronbach's alpha. The data from these questions were the basis for answering two of the three research questions. A retest of participants would ensure a more reliable instrument and possibly identify flaws in the research questions.

Since the identification of certain hidden requirements is a significant finding of this study, there is the possibility that more hidden requirements exist. For example, in retrospect it would be fitting to learn if tenure and promotion requirements emphasize grants as either a written or hidden requirement. Having an open-ended item on the survey may uncover additional hidden requirements that may be useful to computing faculty, particularly those new to the tenure process. There were other, less critical errors that were uncovered in wording that, if improved, could offer 
more clarity in the survey items and provide more reliability. The key changes in future versions of this survey will include the following:

- Piloting of the survey to a variety of faculty across the demographic spectrum.

- Add a question to determine how many years on average it takes to receive tenure and to receive promotion.

- Change the items asking for the amount of funds received from the institution and from any external source to offer an alternative for shared support. For example, clerical staff support may be shared among several faculty and the salary of staff may be unknown.

- Research and expand the informal/formal requirements for tenure sections to add additional categories to uncover more hidden requirements, including whether participants are expected to seek external funding for their research.

- Change the item asking about satisfaction to be rated on a satisfaction scale rather than an agreement scale.

- Review open-ended responses that were provided by participants to include such items as books, book chapters, and more in the research requirements section.

The primary external threat is the self-reported nature of the survey, particularly with the selfperception questions. For example, in response to the survey item "I take research and scholarship seriously," 311 respondents on averaged strongly agreed or agreed with this statement $(M=4.61$, $S D=0.55$ ). This is a highly subjective question and care must be taken in interpreting its relationship to other variables.

Additionally, due to the study focus on computing faculty, the results of this study may not be generalizable to other disciplines. In particular, data gathered regarding tenure and promotion requirements, funding for technology, funding for conferences, and other needs related to the rapidly changing field may be differ significantly among various other disciplines.

\section{Future Work}

Given the significant findings, there is usable information for increasing institutional funding for computing faculty in a manner that could increase faculty satisfaction, tenure and promotion among faculty, and faculty research productivity. In brief, the following studies may further enhance and explain the results of this study. Specifically:

- A longitudinal study could be implemented. The survey items can be revised in light of the open-ended feedback from participants, and then the survey could be administered every two years. This would provide a long-term view of institutional funding and its impact on tenure and promotion requirements.

- An analysis of the relationship between institutional rank and other variables, including tenure and promotion requirements and institutional funding, could be performed.

- An analysis of the relationship between minority status (gender and race) and other variables, including tenure and promotion requirements and institutional funding, could be performed.

- An analysis of the relationship between faculty rank and other variables, including tenure and promotion requirements and institutional funding, could be performed.

- A study exploring the relationship between institutional support and faculty within various disciplines would provide data that could be generalized across disciplines.

\section{Conclusion}

This research provides demographic data about promotion and tenure requirements for computing faculty. The importance of tenure and promotion requirements is clear, as these requirements im- 
pact the careers of faculty and help guide faculty to complete department and institutional goals. In our work, we provide data that has not been previously available, including the identification of hidden requirements for computing faculty. Hidden requirements can exclude qualified candidates who are not aware of their existence or do not believe that the requirement will be evaluated with any level of importance. This can be of particular importance to faculty not embedded deeply into the culture of the department for various reasons, including being new to the department or perhaps being a minority in the department.

In addition to being unaware of hidden requirements, being new to a department can bring further disadvantages that faculty should understand. We find that untenured computing faculty received less staff support, less funding for summer salaries and workshops and training, and less funding for improvements to office space or facilities than their tenured colleagues. It is not known whether department chairs or administrators at institutions are aware of this difference, but a lack of adequate funding in these areas could place untenured faculty at a disadvantage.

This research study also shows that computing faculty are slightly dissatisfied with levels of institutional support and believe that increased funding would improve their research productivity. Computing faculty report that refereed journals and conferences are the most important venues for research and note that collaborations are very important for the promotion and tenure process. Although not specified in written requirements, computing faculty believe that both internal and external collaborative activities are necessary for promotion and tenure. In fact, computing faculty who receive more institutional funding are more likely to engage in internal and external collaborations, though a cause-effect relationship has not been determined.

The lack of satisfaction with institutional support appears to impact computing faculty's perception of the tenure and promotion process. Faculty who agreed that the promotion and tenure process causes them stress did not agree that their institution offers adequate resources, reported that their department or home unit does not value their research, and were not satisfied with the recognition they receive from peer or with their networking opportunities. Computing faculty stressed over the promotion and tenure process believe that mentoring is important, for example in improving the quality if not the quantity of their research, but funding for travel appears to be stagnant.

There are several ways that the issues identified in this study can be corrected. Problems associated with hidden tenure and promotion requirements can be avoided by ensuring that all types of requirements are explicitly covered in writing in a manner that can be evaluated objectively by tenure and promotion committees. To maintain and even increase computing faculty research productivity, institutions and departments can place a greater emphasis on funding additional staff support, including research assistants, more release time, and travel for faculty to attend conferences. These changes would particularly impact untenured faculty, as they are less likely to have adequate funding. Increasing untenured faculty productivity may also have a positive impact on retention by providing them faculty with the support that they require in order to achieve their promotion and tenure requirements.

\section{Acknowledgements}

Thanks to Betsy Bizot and Patrick Krason from the CRA for their assistance in obtaining the Forsythe List and in answering questions about the Taulbee Survey. Thanks to the researchers who designed and conduct the Taulbee Survey for several of the classifications used in our survey instrument. We appreciate Jane Huang's (Depaul University) assistance in providing access to survey tools which enabled us to gather our data. 


\section{References}

Amo, L. C., Ada, S., \& Sharman, R. (2012). The role of scholar status in the academic publication process. International Journal of Doctoral Studies, 7, 79-92.

Athey, S., \& Plotnicki, J. (2000). An evaluation of research productivity in academic IT. Communications of the Association for Information Systems, 3(7).

Blackburn, R. T., Bieber, J. P., Lawrence, J. H., \& Trautvetter, L. (1991). Faculty at work: Focus on research, scholarship, and service. Research in Higher Education, 32(4), 385-413.

Brocato, J., \& Mavis, B. (2005). The research productivity of faculty in family medicine departments at U.S. medical schools: A national study. Academic Medicine, 80(3), 244-252.

Bunton, S. A., \& Mallon, W. T. (2007). The continued evolution of faculty appointment and tenure policies at U.S. medical schools. Academic Medicine, 82(3), 281-289.

Caffarella, R. S., \& Zinn, L. F. (1999). Professional development for faculty: A conceptual framework of barriers and supports. Innovative Higher Education, 23(4), 241-254.

Camp, T. 1997. The incredible shrinking pipeline. Communications of the ACM, 40(10).

Carnegie Foundation for the Advancement of Teaching. (1991). Research-intensive vs. teaching-intensive institutions. Change, May/June, 23(3).

Computing Research Association. (1999, September). Best practices memo. Evaluating computer scientists and engineers for promotion and tenure. Computing Research News.

Computing Research Association. (2012, March). Computer Science Post-docs. Retrieved from http://cra.org/postdocs/

Conrad, L. (1998). Enhancing research through academic staff development. International Journal for Academic Development, 3(2), 114-123.

Creswell, J. W. (2008). Educational research. planning, conducting, and evaluating quantitative and qualitative research. Upper Saddle River, New Jersey: Pearson Education.

Dee, J. R. (2004). Turnover intent in an urban community college: Strategies for faculty retention. Community College Journal of Research and Practice, 28(7), 593-607.

Dennis, A. R., Valachich, J. S., Fuller, M. A., \& Schneider, C. (2006). Research standards for promotion and tenure in information systems 1. MIS Quarterly, 30(1).

Dundar, H., \& Lewis, D. R. (1998). Determinants of research productivity in higher education. Research in Higher Education, 39(6).

Dunham-Taylor, J., Lynn, C. W., Moore, P., McDaniel, S., \& Walker, J. K. (2008). What goes around comes around: Improving faculty retention through more effective mentoring. Journal of Professional Nursing, 24(6), 337-346.

Ehrenberg, R., Kasper, H., \& Rees, D. (1991). Faculty turnover at American colleges and universities: Analyses of AAUP data. Economics of Education Review, 10(2), 99-110.

Fairweather, J. S. (2002). The mythologies of faculty productivity: Implications for institutional policy and decision making. Journal of Higher Education, 73(1), 26-48.

Fletcher, J. J., \& Patrick, S. K. (1998). Not just workshops any more: The role of faculty development in reframing academic priorities. International Journal for Academic Development, 3(1), 39-46.

Franceschet, M. (2010). The role of conference publications in CS. Communications of the ACM, 53(12).

Freedenthal, S., Potter, C., \& Grinstein-Weiss, M. (2008). Institutional supports for faculty scholarship: A national survey of social work programs. Social Work Research, 32(4).

Glassick, C. E., Huber, M. T., \& Maeroff, G. I. (1997). Scholarship assessed: Evaluation of the professoriate. Special report. Jossey Bass Inc. 
Greene, H. C., O’Connor, K. A., Good, A. J., Ledford, C. C., Peel, B. B., \& Zhang G. (2008). Building a support system toward tenure: Challenges and needs of tenure-track faculty in colleges of education. Mentoring \& Tutoring: Partnership in Learning, 16(4), 429-447.

Gruppen, L. D., Frohna, A. Z., Anderson, R. M., \& Lowe, K. D. (2003). Faculty development for educational leadership and scholarship. Academic Medicine, 78(2), 137-141.

Halpern, J. Y., \& Parkes, D. C. (2011). Journals for certification, conferences for rapid dissemination. Communications of the ACM, 54(8), 36-38.

Harris, M. B. (1997). Basic statistics for behavioral science research. Allyn \& Bacon.

Meho, L. I., \& Spurgin, K. M. (2005). Ranking the research productivity of library and information science faculty and schools: An evaluation of data sources and research methods. Journal of the American Society for Information Science and Technology, 56(12), 1314-1331.

Olsen, D. (1993). Work satisfaction and stress in the first and third year of academic appointment. Journal of Higher Education, 64(4), 453-471.

Olsen, D., Maple, S. A., \& Stage, F. K. (1995). Women and minority faculty job satisfaction: Professional role interests, professional satisfactions, and institutional fit. Journal of Higher Education, 66(3).

Park, B., \& Riggs, R. (1993). Tenure and promotion: A study of practices by institutional type. The Journal of Academic Librarianship, 19(2), 72-77.

Petry, J., \& Kenney G. (1991). The impact on higher education. Part of a symposium on Funding Shortfalls and Their Impact on Policy Making in the 1990s at the Annual Meeting of American Educational Studies Association. Kansas City, MO.

Piercy, F., Giddings, V., Allen, K., Dixon, B., Meszaros, P., \& Joest, K. (2005). Improving campus climate to support faculty diversity and retention: A pilot program for new faculty. Innovative Higher Education, 30(1), 53-66.

Research Assessment Exercise. (2008). RAE 2008 quality profiles. Retrieved June 2011 from http://www.rae.ac.uk/aboutus/quality.asp

Rosser, V. (2005). Measuring change in faculty perceptions over time: An examination of their worklife and satisfaction. Research in Higher Education, 46(1), 81-107.

Shaw, V.N. (2002). Counseling the university professor on the securing of research grants and the publishing of research products. Education, 123(2).

Schuster, J. H. (1986). The faculty dilemma: A short course. The Phi Delta Kappan, 68(4), 275-282. Retrieved June 2011 from http://www.jstor.org/stable/20403335

Solem, M. N., \& Foote, K. E. (2004). Concerns, attitudes, and abilities of early-career geography faculty. Annuals of the Association of American Geographers, 94(4), 889-912.

Stanley, D. T. \& Campbell, J. C. (1963). Experimental and quasi-experimental designs for research. USA: Houghton Mifflin Company.

Thomas, P. A., Diener-West, M., Canto, M. I., Martin, D. R., Post, W. S., \& Streiff, M. B. (2004). Results of an academic promotion and career path survey of faculty at the Johns Hopkins University School of Medicine. Academic Medicine, 79(3), 258-264.

U.S. Department of Education. National Center for Education Statistics. (1993). Database of the 1993 National Study of Postsecondary Faculty (NSOPF-93). Retrieved from http://nces.ed.gov/pubsearch/pubsinfo.asp?pubid=97467

U.S. Department of Education. National Center for Education Statistics. (1999). Database of the 1999 National Study of Postsecondary Faculty (NSOPF-99). Retrieved from http://nces.ed.gov/pubsearch/pubsinfo.asp?pubid=2002154

U.S. Department of Education. National Center for Education Statistics. (2004). Database of the 2004 National Study of Postsecondary Faculty (NSOPF-04). Table 16 Percentage of full-time instructional fac- 
ulty and staff who were very satisfied with their instructional duties and employment conditions and percentage who would choose an academic career again, by institution type, gender, and experience. Retrieved from http://nces.ed.gov/das/library/tables_listings/nsopf.asp

Walfish, S. (2006). A review of statistical outlier methods. Pharmaceutical Technology. Retrieved from http://www.pharmtech.com/pharmtech/IT/A-Review-of-Statistical-OutlierMethods/ArticleStandard/Article/detail/384716

Xu, Y. J. (2008). Faculty turnover: Discipline-specific attention is warranted. Research in Higher Education, 49, 40-61.

Youn, T. I. K., \& Price, T. M. (2009). Learning from the experience of others: The evolution of faculty tenure and promotion rules in comprehensive institutions. Journal of Higher Education, 80(2), 204237.

Zweben, S. (2010). Undergraduate CS enrollment continues rising; Doctoral production drops: 2008-2009 Taulbee Survey. Computing Research News, 22(3).

\section{Appendix}

In this appendix, we provide the instrumentation used for collecting participant data.

\section{Consent Request}

\section{Demographic Data}

2. Please indicate your race/ethnicity. Mark as many as are applicable:

Non-resident alien

American Indian or Alaska Native

Asian

Black or African-American/Canadian

Native Hawaiian or Pacific Islander

White

Multi-racial, not Hispanic

Resident Hispanic, any race

3. Please indicate your sex: Male Female

4. Please indicate your status: Full-time Part-time or Adjunct Emeritus

5. Please indicate the type of academic calendar for your institution:

Semester

Quarter

Other

6. How many courses do you teach each academic year as part of your official teaching load?

7. Your institution is located in:
United States
Canada

8. Select the type of department (or school in the case of institutions that organize differently)

you are in:

Computer Science

Computer Engineering

Electrical Engineering

Information (including Information Systems)

Other (please specify): 
9. For stratifying your responses with the original Taulbee suvey, please select your institution:

Stanford, Massachusetts Institute of Technology, University of California (Berkeley), Carnegie Mellon, Cornell, Princeton, University of Texas (Austin), University of Illinois (Urbana-Champaign), University of Washington, University of Wisconsin (Madison), Harvard, or California Institute of Technology

Brown, Yale, University of California (Los Angeles), University of Maryland (College Park), New York University, University of Massachusetts (Amherst), Rice, University of Southern California, University of Michigan, University of California (San Diego), Columbia, or University of Pennsylvania

University of Chicago, Purdue, Rutgers, Duke, University of North Carolina (Chapel Hill), University of Rochester, State University of New York (Stony Brook), Georgia Institute of Technology, University of Arizona, University of California (Irvine), University of Virginia, or Indiana

Other

10. Please indicate your academic rank:

Full Professor

Associate Professor

Assistant Professor

Non-tenure track teaching faculty

Non-tenure track research faculty

Postdoctorate

Other (please specify):

11. Estimate the number of publications that are required for promotion and/or tenure at your institution (answer one or more):

Per academic year:

During the entire probationary period:

During the entire period reviewed for promotion:

12. Please rank the following characteristics of publication for tenure/promotion at your department as Unimportant, Of Little Importance, Moderately Important, Important, or Very Important:

Quantity of Publications

Acceptance Rate of the venue in which publications appear

Ranking of the venue in which publications appear

Scope of the venue in which publications appear, eg. International, national, or regional

13. Please rank the importance of the following characteristics of tenure/promotion at your department as Unimportant, Of Little Importance, Moderately Important, Important, or Very Important:

Refereed Conferences

Non-refereed Conferences

Refereed Journals

Non-refereed Journals

Other (please specify): 
14. Indicate which of the following types of collaborations are necessary to obtain tenure and promotion at your institution as Formally Required (written policy), Informally Required (culture/environment), or Not Required (informally or formally):

Internal to the Institution

External to the Institution

15. Indicate which of the following types of collaborative activities are necessary to obtain tenure and promotion at your institution as Formally Required (written policy), Informally Required (culture/environment), or Not Required (informally or formally):

Projects

Publications

Grants

Presentations

Other (please specify):

16. How many presentations have you given at conferences and professional meetings in the last academic year?

17. How many publications have you had in the last academic year, including journal articles, book chapters, conference proceedings, reviews, abstracts, books, or any other type of professional-academic writing?

\section{Institutional support and resources}

18. Please indicate what support and/or resources you received from ANY source (your institution or any external source) during the 2009-2010 academic year:

Funds to attend professional meetings

Funds to attend conferences

Improvements to office space or facilities

Improvements to other space(s) (research lab, studio space, etc.)

Computer purchase or upgrade

Research lab upgrades

Funds for release time

Stipend

Summer salary

Mentorship (informal or formal)

Staff support (research assistants, clerical, other)

Flexibility about the tenure clock

Grant writing support or seminars

Promotion and tenure seminars

Workshops or training

Tuition remission for you

Other (please specify)

19. For each of the following, please estimate the amount of funds you received from your INSTITUTION:

Funds to attend professional meetings

Funds to attend conferences

Improvements to office space or facilities

Improvements to other space(s) (research lab, studio space, etc.) 
Computer purchase or upgrade

Research lab upgrades

Funds for release time

Stipend

Summer salary

Mentorship (informal or formal)

Staff support (research assistants, clerical, other)

Flexibility about the tenure clock

Grant writing support or seminars

Promotion and tenure seminars

Workshops or training

Tuition remission for you

\section{Perceptions}

20. The support faculty received at my institution in the 2009-2010 academic year:

Increased from the 2008-09 academic year

Stayed the same as the 2008-09 academic year

Decreased from the 2008-09 academic year

21. For each item below, please indicate your agreement with each of the following statements as Not Applicable, Strongly disagree, Disagree, Undecided, Agree, Strongly Agree:

I am a very productive researcher.

I take research and scholarship seriously.

My department/home unit values my research.

My research has a good reputation in my discipline.

Mentoring by research peers is important to me.

Mentoring by research peers has improved the quality of my research/publications.

Mentoring by research peers has improved the quantity of my

research/publications.

My research has attracted interest from my peers.

My institution offers adequate resources for faculty to perform their research.

I am satisfied with my opportunities for networking in my discipline.

I am satisfied with my opportunities for research collaboration.

I am satisfied with the recognition I receive from my peers in my discipline.

The tenure and promotion process causes me an unreasonable amount of stress.

As part of my position, I am expected to seek external funds to fund my research.

22. Please indicate your satisfaction with your institution for each of the following items as Not Applicable, Strongly disagree, Disagree, Undecided, Agree, Strongly Agree:

Being funded to attend professional meetings

Being funded to attend conferences

Improvements to office space or facilities

Improvements to other space(s) (research lab, studio space, etc.)

Computer purchases or upgrade

Research lab upgrades

Release time

Stipends

Summer salary

Mentorship (informal or formal) 
Staff support (research assistants, clerical, other)

Flexibility about the tenure clock

Grant writing support or seminars

Promotion and tenure seminars

Workshops or training

Tuition remission for you

23. Select up to three areas where you think if your institutional support increased, you believe your research productivity would increase:

Being funded to attend professional meetings

Being funded to attend conferences

Improvements to office space or facilities

Improvements to other space(s) (research lab, studio space, etc.)

Computer purchases or upgrade

Research lab upgrades

Release time

Stipends

Summer salary

Mentorship (informal or formal)

Staff support (research assistants, clerical, other)

Flexibility about the tenure clock

Grant writing support or seminars

Promotion and tenure seminars

Other (please specify):

\section{Biographies}

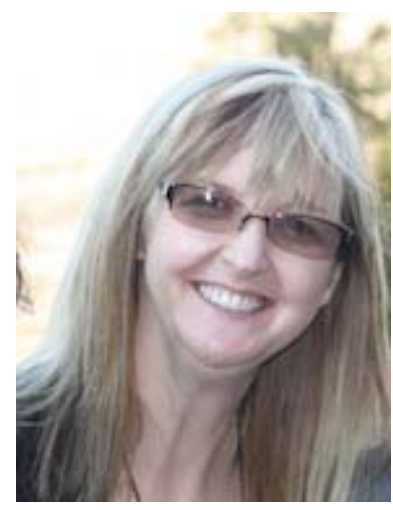

Monica M. McGill is an Assistant Professor in the Department of Interactive Media at Bradley University, where she serves as the Lead of the Game Design concentration. She holds a B.S. in Computer Science and Mathematics (University of Illinois), M.S. in Computer Science (George Washington University), and Ed.D. in Curriculum and Instruction (Illinois State University). Her primary research interests include computing education and game curriculum.

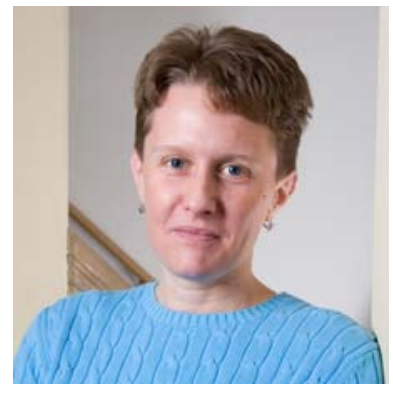

Amber Settle is an Associate Vincent de Paul Professor at DePaul University and has a full-time faculty member since September 1996. She holds a B.S. in Mathematics and a B.A. in German (University of Arizona), and a M.S. and Ph.D. in computer science (University of Chicago). Her research interests include computer science, information technology, and gaming education, computational thinking, cellular automata, and distributed algorithms. She has served on the Advisory Board for the Special Interest Group for Computer Science Education (SIGCSE) since 2010, is a member of the Editorial Advisory Board for ACM Inroads, and serves on the Editorial Review Boards for the Journal of Information Technology: Research and Journal of Information Technology: Innovations in Practice. 